\title{
"TU SABE? TE LEMBRA?": O RESGUARDO DE INFORMAÇÕES EM INTERROGATÓRIOS POLICIAIS POR MEIO DA (COM)POSIÇÃO DE PERGUNTAS E RESPOSTAS
}

\author{
"Do you know? Do you remember?": \\ Information Safeguarding in \\ "¿Tú sabes? ¿Te acuerdas?": \\ Protegiendo Información en los \\ Police Interrogations through the \\ Interrogatorios Oficiales a través de la \\ (Com)Position of Questions and Answers \\ (Com)Posición de Preguntas y Respuestas
}

\author{
Paola Gabriela Konrad* \\ Ana Cristina Ostermann** \\ Universidade do Vale do Rio dos Sinos \\ Escola da Indústria Criativa \\ São Leopoldo, RS, Brasil
}

\begin{abstract}
Resumo: Este artigo analisa sequências de perguntas e respostas em um evento institucional por elas permeado: o interrogatório policial. Investiga, pela perspectiva teórico-metodológica da Análise da Conversa Multimodal, como acontece o resguardo de informações acerca dos crimes em interrogatórios policiais de três Delegacias de Polícia Civil. A análise dos interrogatórios gravados em áudio e/ou vídeo evidencia que esse resguardo, além de ser realizado nas respostas dos interrogados acusados por crimes é, também, oportunizado pelos próprios policiais em suas perguntas. Os interrogados resguardam os fatos dos crimes ao resistirem ao provimento das informações solicitadas, fornecendo respostas cujas ações consistem em declarações de desconhecimento, deslembrança e dessaber, dentre outras. Já os policiais oportunizam esse resguardo ao realizarem perguntas que integram a seleção lexical de verbos como saber e lembrar, possibilitando - e até mesmo facilitando - que os interrogados respondam dessaber e/ou deslembrar a informação solicitada sem resistir ao formato da pergunta.
\end{abstract}

Palavras-chave: Interrogatório Policial. Pergunta. Resposta. Análise da Conversa Multimodal.

\begin{abstract}
This paper analyzes questions and answers - a type of sequence that is constitutive of police interrogations. By means of Multimodal Conversation Analysis, it investigates how the safeguarding of information concerning crimes unfolds in police interrogations. A fine-grained sequential and multimodal analysis of the audio and/or video recorded interrogations reveals that the safeguarding of information is accomplished not only by the interrogated suspects in their responsive actions, but also ensued by the police officers by means of their question design. Interrogated suspects safeguard facts about crimes by resisting in providing the information requested in responsive turns that do not answer but that instead claim lack of knowledge, remembrance or awareness. Police officers, on the other hand, afford and initiate suspects' information safeguarding by designing questions with verbs as to know and to remember. Such question design vouchsafes suspects to negate knowledge and remembrance of the requested information while aligning with the preference of the question format and presenting no resistance.
\end{abstract}

Keywords: Police Interrogation. Question. Answer. Multimodal Conversation Analysis.

* Doutoranda em Linguística Aplicada. Programa de Pós-graduação em Linguística Aplicada, UNISINOS. ORCID: https://orcid.org/0000-0001-9150-9627 E-mail: paolagkonrad@gmail.com.

** Doutora em Linguística. Docente do Programa de Pós-graduação em Linguística Aplicada, UNISINOS. ORCID: https://orcid.org/0000-0001-9017-6314 E-mail: aco@unisinos.br. 
Resumen: Este artículo analiza secuencias de preguntas y respuestas en un evento institucional por ellas permeado: el interrogatorio policial. Investiga, por la perspectiva teórico-metodológica del Análisis de la Conversación Multimodal, cómo acontece la protección de informaciones sobre crímenes en interrogatorios policiales de tres Estaciones de Policía Civil. El análisis de los interrogatorios grabados en audio y/o video hace evidente que esa protección, allá más de ser realizada en las respuestas de los interrogados acusados de crímenes, también es una oportunidad que los propios policiales les dan en sus preguntas. Los interrogados protegen los factos sobre los crímenes cuando resisten de proporcionar las informaciones solicitadas, forneciendo respuestas cuyas acciones consisten en declaraciones de desconocimiento, de no acordaren y no saber, entre otras. Ya los policiales crean oportunidad para esa protección cuando realizan preguntas que integran la selección léxica de verbos tales cuales saber y acordar, haciendo posible - y hasta mismo haciendo más sencillo - que los interrogados contesten no saber y/o no se acordar de la información solicitada, sin resistir al formato de la pregunta.

Palabras clave: Interrogatorio Policial. Pregunta. Respuesta. Análisis de la Conversación Multimodal..

\section{INTRODUÇÃO}

O sociólogo Harvey Sacks, ao explicar o funcionamento de perguntas na fala-eminteração, inicia, nos anos de 1960, uma de suas conhecidas aulas catedráticas (que integra a coletânea "Lectures on Conversation", publicada em 1992) com narrativas, que reproduzimos a seguir, de forma sintetizada (SACKS, 1992). A primeira delas trata-se de uma piada ídiche: um jovem, após entrar em um trem, senta-se ao lado de um homem mais velho. Ao perguntar para seu vizinho de poltrona "você pode me dizer as horas?", recebe um "não" em resposta. "Como assim 'não'?", pergunta o jovem. O homem mais velho explica: "se eu lhe disser a hora, vamos ter que começar a conversar. Você vai me perguntar para onde eu estou indo e eu vou lhe perguntar aonde você está indo. Descobriremos que estamos indo para o mesmo lugar. Eu terei que lhe convidar para jantar. Eu tenho uma filha em idade para casar, e eu não quero que ela se case com alguém que não usa um relógio".

A outra história teria sido presenciada por Sacks em um aeroporto. Conta ele que um grupo de cerca de 20 pessoas aguarda a chegada de um avião. Uma jovem encontrase de pé. Um rapaz chega atrás dela e pergunta "que horas chega o avião?". Ao se virar, ela responde "em 20 minutos", e retorna à sua posição inicial. Eis que o rapaz faz outra pergunta. A jovem se volta para ele, responde, e vira-se novamente. Isso continua por mais cinco ou seis perguntas. Ela, então, simplesmente vira seu corpo em direção a ele, sem nenhuma expressão em especial, ou mesmo olhando para ele. O rapaz continua fazendo perguntas, e ela, respondendo-as. A jovem ergue a cabeça ao responder e a abaixa novamente. Então, parece que a qualquer momento ele vai parar de perguntar. Em determinado instante, a jovem tira um cigarro e ele o acende.

Sacks argumenta que parece haver uma regra tácita de que a pessoa que pergunta tem o direito de falar novamente depois que a sua pergunta é respondida; e essa regra pode acabar gerando longas sequências interacionais do tipo pergunta-resposta, pergunta-resposta, e assim por diante. É o que se vê acontecer, de certa forma, na história da fila do aeroporto. Cada pergunta respondida abre espaço para uma nova pergunta, e essa nova pergunta, assim que respondida, gera a oportunidade para outra pergunta e, assim, sucessivamente. Entretanto, observe-se que, na piada ídiche, ao responder simplesmente com "não" à pergunta inicial "você pode me dizer as horas?", o homem mais velho acaba por atravancar a oportunidade de uma conversa se desenvolver. 
Esse homem, ao responder com "não", revela sua competência-em-ação (BITTNER, 2013 [1965]) $)^{1}$ sobre os etnométodos ${ }^{2}$ que os interagentes usam para ocasionar o espaço interacional - um espaço que pode se desenvolver para muito além de apenas uma única troca de informação. Primeiro, porque ao responder com "não", ele atende ao formato do que lhe fora perguntado ("você pode X"?); isto é, responde a uma pergunta de "sim" e "não", e não atende à ação propriamente que lhe fora solicitada: a de informar a hora. Segundo, porque ele também verbaliza o etnométodo empregado pelo perguntador ao descrever, com todas as letras, aonde aquela "mera" pergunta inicial vai culminar: em uma sequência de várias outras perguntas que poderá ocasionar, inclusive, um relacionamento mais longo.

Observe-se ainda que, ao formular sua pergunta "você pode me dizer as horas", o rapaz se utiliza de duas orações ("você pode" e "me dizer as horas"), configurando não apenas um pedido de informação sobre as horas, como também um simples pedido acerca da possibilidade do provimento das horas. Se o jovem simplesmente perguntasse "que horas são?" ou "por favor, que horas são?", seu vizinho de poltrona teria, por certo, um maior trabalho interacional para negar o provimento da informação solicitada, haja vista que o pedido, quando feito nesses outros formatos, não torna relevante respostas como "sim" ou "não".

Essas duas narrativas são por demais relevantes ao objeto de interesse deste artigo, sequências de perguntas e respostas, bem como os seus desdobramentos e não desdobramentos, em interrogatórios policiais gravados e transcritos. $\mathrm{O}$ interrogatório policial, como se sabe, consiste em um evento interacional tipicamente permeado por sequências de perguntas e respostas, nas quais um dos falantes assume a tarefa de perguntar (neste caso, o investigador) enquanto do outro se espera que assuma a tarefa de responder (neste caso, o interrogado acusado pelo crime sob investigação) (ANDRADE; OSTERMANN, 2007).

Apesar de alguns aspectos do interrogatório policial, sobretudo as informações que devem ser solicitadas aos acusados, serem predeterminados por disposições legais (BRASIL, 2003), a maneira como cada policial interroga resulta da (re)produção de regras circunscritas a um estatuto local para que se cumpra o "mandato" (LYNCH; BOGEN, 1996) de apuração dos crimes sob investigação. Essas regras, que derivam da perspicácia e da experiência situada dos policiais, adquirem sentido no caráter ordenado das interações (SACKS, 1984), isto é, quando as regras são sequencial e reflexivamente empregadas pelos investigadores. E, embora inexistam no Brasil ${ }^{3}$ documentos (ou manuais) de técnicas e/ou métodos de interrogação policial acerca de crimes (PINTO, 2015), compreendemos que o interrogatório policial não é “[...] diretamente dedutível de

${ }^{1}$ A expressão "competência-em-ação" deriva da etnografia das práticas e competências dos policiais, desenvolvida no trabalho seminal do sociólogo e fenomenologista Egon Bittner (2013 [1965]) (MEEHAN, 2018). Apesar de no estudo de Bittner a expressão restringir-se às práticas policiais, o corpus deste estudo possibilita a expansão da noção de "competência-em-ação" para a análise dos recursos acionados pelos interrogados nos turnos de fala responsivos.

${ }^{2}$ Etnométodos consistem nos métodos de produção de sentido utilizados pelas pessoas enquanto interagem (GARFINKEL, 1967).

${ }^{3}$ Conforme relatado pelos próprios policiais participantes da pesquisa que gerou este artigo, há, também, uma lacuna no processo formativo dos investigadores no que concerne à prática de interrogar. 
regras escritas" (LIBERMAN, 2013, p. 119), uma vez que é no aqui-e-agora interacional que a prática de interrogar se efetiva.

Em resposta à prática de interrogar encontra-se (e espera-se) a de responder. Nos turnos de fala responsivos às perguntas dos investigadores, os interrogados têm autonomia para prover (ou não) as informações solicitadas. Ao encontro desse livrearbítrio, está o seu direito à autodefesa, dado que é por meio das respostas que os acusados podem alegar inculpabilidade acerca da imputação que lhes é atribuída.

É justamente o espaço interacional entre uma pergunta e sua resposta (i.e., o par adjacente $^{4}$ pergunta-resposta) que este estudo se propõe a investigar. Tendo em vista que "[...] o interrogatório é uma forma de diálogo que instancia a possibilidade de uma análise lógica, intrínseca à sua própria realização" (LYNCH; BOGEN, 1996, p. 128), examinase, por meio da perspectiva teórico-metodológica da Análise da Conversa Multimodal de base etnometodológica (SACKS; SCHEGLOFF; JEFFERSON, 1974; SACKS, 1992; MONDADA, 2014) (doravante AC), como acontece o resguardo de informações acerca dos crimes sob investigação em interrogatórios policiais de três Delegacias de Polícia Civil do Estado do Rio Grande do Sul, Brasil.

\section{A COMPOSIÇÃO DE PERGUNTAS E RESPOSTAS}

O formato dos turnos de fala (SACKS, 1992; SCHEGLOFF, 1984a; 1993; 2007; DREW, 2013) - também tratado nos estudos da AC como composição desses turnos (SCHEGLOFF, 1984a; 1993; 2007; STIVERS, 2013; CLIFT, 2016) - por meio dos quais as pessoas realizam as ações de perguntar e de responder (dentre inúmeras outras ações) resume-se a como a ação interacional é produzida. Dito de outra forma, o formato ou a composição dos turnos de fala refere-se a como determinada ação social toma forma em uma interação (CLIFT, 2016) e a como essa ação é reconhecida pelos interagentes como sendo $\mathrm{X}$ e não $\mathrm{Y}$.

Em relação às perguntas, o corpus que integra este estudo e que será apresentado $a$ posteriori evidencia que um desses formatos consiste no número de orações com que a ação de pedir informação é apresentada. Por exemplo, em "você lembra qual era o nome dele?", há duas orações que configuram duas perguntas interligadas ("você lembra" e "qual era o nome dele"). Observe-se que um pedido de informação com o formato "você lembra qual era o nome dele?" tem implicações distintas de "qual era o nome dele?", implicações essas, que este artigo se propõe a discutir a partir de uma perspectiva interacional multimodal.

Também as escolhas lexicais dão forma à composição de turnos de fala. Tais escolhas, como veremos neste artigo, acabam por repercutir em consequências distintas para as interações. Nos dados desta pesquisa, a composição de turnos que perguntam e

\footnotetext{
$4 \mathrm{O}$ par adjacente consiste na sequência mínima de uma interação. Ele constitui-se de duas partes (cada qual produzida por um falante diferente), que são sequencialmente ordenadas e relacionadas, no sentido de que a produção de certa $1^{\mathrm{a}}$ ação gera a relevância sequencial para determinada $2^{\mathrm{a}}$ ação $-\mathrm{e}$ não qualquer outra $2^{a}$ ação (e.g., pedido de informação-provimento de informação, convite-aceite/recusa, cumprimento-cumprimento, etc.) (SCHEGLOFF, 2007).
} 
que respondem frequentemente envolve a seleção lexical de verbos como "saber" e "lembrar". Esses verbos, numa perspectiva linguístico-cognitiva - perspectiva que se distancia do estudo aqui proposto - denominam-se "verbos de cognição" (COSTA; CUNHA, 2016) e correspondem a processos mentais relacionados à memória, à decisão, à compreensão, à crença e ao planejamento, tais como: “[...] decidir, considerar, achar, supor, acreditar, imaginar, lembrar, esquecer, saber, entender, perceber, compreender, pensar [...]" (COSTA; CUNHA, 2016, p. 251).

Por outro lado, na abordagem do "aqui-e-agora" interacional, abordagem na qual este estudo encontra-se alicerçado, esses verbos ancoram-se nas ações comunicativas desempenhadas por membros competentes de uma comunidade linguística (LYNCH; BOGEN, 2005). Dito de outra forma, fenômenos mentais, numa perspectiva sacksoniana $^{5}$, não se constituem intrínsecos a processamentos mentais ou a operações cognitivas, mas parte constituinte "[...] da maquinaria linguística e cultural das ações e interações sociais" (WATSON, 1994, p. 183).

\section{DESSABER, DESLEMBRANÇA, (NÃO) CONFORMIDADE E (DES)PREFERÊNCIA}

Ao analisar interações entre conselheiros tutelares e crianças, o sociólogo Hutchby (2002) constata que respostas como "eu não sei" e "eu não conheço", ao desempenhar, na sequencialidade do turno a turno, ações de dessaber e desconhecimento, operam como resistência (ou não cooperação) ao provimento de informações. Similarmente, Lynch e Bogen (1996), ao investigar a tomada de depoimentos de testemunhas do caso "IrãContras"6, observam que as recorrentes respostas dos interrogados consistem em declarações de deslembrança. Essas respostas, segundo os autores, evidenciam a maneira com a qual testemunhas são capazes de resistir ao que é perguntado, de forma a deslocar a força do interrogatório, uma vez que respostas como "não lembro" tendem a neutralizar (no sentido de atenuar) e, até mesmo estagnar, a busca pela verdade dos fatos (LYNCH; BOGEN, 1996).

Respostas como essas constituem-se, em sua sequencialidade interacional, "não conformativas" (RAYMOND, 2003), i.e., não correspondendo ao que é tornado relevante nas perguntas, tanto em termos da ação solicitada como também do formato. Um exemplo prototípico desse tipo de resposta seria o provimento de "não sei" em resposta à pergunta "quem estava na festa ontem?".

As noções de "conformidade" e de "não conformidade", por sua vez, estão associadas ao conceito de "organização de preferência" (POMERANTZ, 1984). A

\footnotetext{
${ }^{5}$ Refere-se aqui aos fundamentos da "mentalidade analítica" da Análise da Conversa, propostos por Harvey Sacks.

6 "Irã-Contras", que veio à tona em 1986, foi um acontecimento político nos Estados Unidos sobre o envolvimento de funcionários do governo Reagan no tráfico ilegal de armas ao Irã. A venda de armas para os iranianos integrava uma negociação que tinha como propósito a liberação de reféns norteamericanos no Líbano durante conflito no Oriente Médio. A investigação, comandada pelo Congresso dos Estados Unidos, atribuiu a responsabilidade do fato a funcionários do governo, incluindo Reagan (HISTORY PLAY, 2019).
} 
organização de preferência corresponde a um escalonamento (de preferência) que certas ações responsivas apresentam em relação a outras. Por exemplo, diante de uma primeira ação (um convite, por exemplo), abre-se o espaço de relevância interacional para basicamente duas ações responsivas: aceitar ou não aceitar o convite. Contudo, essas duas segundas ações não têm o mesmo status diante de um convite. Enquanto o aceite se afilia (e, portanto, consiste em uma ação preferida), o não aceite se desafilia (sendo uma ação despreferida). Ações responsivas consideradas "preferidas" são normalmente curtas e produzidas de forma imediata, sem atraso temporal. Em contrapartida, ações responsivas "despreferidas" tendem a ser produzidas com atraso temporal, iniciadas com marcadores discursivos como "bem" e "olha só", hesitação e justificativas (POMERANTZ, 1984).

Volta-se, agora, para os conceitos de "conformidade" e de "não conformidade". Tendo em vista que uma resposta é entendida como conformativa quando atende ao que fora solicitado na pergunta, ao passo que, quando não atende, é considerada não conformativa, respostas conformativas e não conformativas mostram-se associadas à organização de preferência (RAYMOND, 2003): as conformativas são geralmente preferidas, enquanto que as não conformativas são comumente consideradas despreferidas.

As respostas investigadas nos dois estudos descritos no início desta subseção (respostas como "não sei", "não conheço" e "não lembro") são, além de não conformativas, também despreferidas, uma vez que revelam desafiliação e resistência em relação ao que é perguntado. Tal achado encontra-se, como veremos na primeira seção analítica deste artigo, em alinhamento com o que procede em parte dos interrogatórios analisados neste estudo.

\section{ANÁLISE DA CONVERSA}

Este artigo ampara-se na abordagem teórico-metodológica da AC Multimodal de base etnometodológica (SACKS; SCHEGLOFF; JEFFERSON, 1974; SACKS, 1992; MONDADA, 2014). Essa perspectiva, por meio da qual analisam-se interações naturalísticas, advém, como o próprio nome sugere, da etnometodologia (GARFINKEL, 1967) - uma vertente da sociologia.

A natureza etnometodológica da abordagem da fala-em-interação se baseia numa descrição altamente granular das práticas e competências que membros de uma sociedade assumem para produzir, de maneira mútua, uma ordem social reconhecível (MEEHAN, 2018). Vale-se, portanto, do olhar dos próprios participantes de uma interação para que se compreenda o que eles estão fazendo (SILVA; ANDRADE; OSTERMANN, 2009). As evidências, assim, encontram-se na própria interação: na organização das práticas conversacionais propriamente ditas, cujos desdobramentos revelam o entendimento dos falantes em relação ao que procede na interação (SCHEGLOFF, 1997).

Os etnométodos acionados pelos interagentes para dar sentido ao que acontece em uma interação perpassam dois conceitos indissociáveis para as análises interacionais: (i) ação, i.e., o que as pessoas fazem por meio de seus turnos de fala e/ou por meio de outros 
recursos não-verbais (e.g., ações como pedido de informação, convite, negação, reclamação, avaliação, etc.); e (ii) sequência, que consiste em um curso de ações implementado por cada ação na conversa e por sua contiguidade/adjacência - como uma ação leva à outra (CLIFT, 2016). Dessa maneira, o objeto de investigação da AC não se limita a ações isoladas, mas constitui-se da relação de cada nova ação com o que acontecera antes e o que é produzido depois (por isso, "sequência"). Analisam-se, assim, as ações implementadas por meio de turnos de fala e por condutas corporificadas em seu contexto sequencial (sua posição em uma sequência de outras ações, precedentes e consequentes). Essa ordenação sequencial é ocasionada in situ pelos próprios interagentes (WATSON; GASTALDO, 2015). Tal concepção endógena constitui-se essencial para a análise que será apresentada a posteriori.

Também faz-se necessário esclarecer o caráter multimodal das interações face-aface e, por consequência, das investigações atuais pela perspectiva da AC. Lorenza Mondada (2019, p. 50), ao pautar os estudos dos primeiros pesquisadores que se mostraram interessados pela análise da corporificação nas interações (GOODWIN, 1981a, b; HEATH, 1983, 1986; SCHEGLOFF, 1984b; SACKS; SCHEGLOFF [1975]/2002), explica que "o estudo da análise da conversa etnometodológica caracterizase por um número crescente de recursos corporificados a serem considerados". A natureza multimodal da abordagem da fala-em-interação, assim, dá conta da "diversidade de recursos mobilizados pelos participantes para produzir e entender a interação social como ações socialmente inteligíveis" (MONDADA, 2019, p. 47). Isso significa olhar para a fala (que aqui inclui também a modalidade de fala sinalizada) combinada a outros recursos semióticos, tais como gestos, posturas corporais, olhares, e a manipulação corporificada de objetos (MONDADA, 2019); em outras palavras, os "recursos não-verbais".

Para que seja possível analisar essa "ecologia de sistemas semióticos" (CRUZ et al., 2019) por meio da qual se constroem ações sociais (GOODWIN, 2010), necessita-se levar em conta a minuciosa coordenação de temporalidades complexas que envolvem tais recursos (CRUZ et al., 2019; ANDRIOLI; OSTERMANN, 2019). Dito de outra forma, é fundamental considerar as produções verbais de forma associada à temporalidade das estruturas corporificadas de participação em uma interação (STREECK et al., 2011), uma vez que as ações sociais são também desempenhadas de maneira não verbal e, sobretudo, em associação entre o verbal e o não verbal. À vista disso, o caráter multimodal da abordagem interacional não pressupõe uma segmentação entre o material verbal e o que é corpóreo ou referente ao mundo dos objetos manipulados pelos interagentes. É justamente a coordenação desses etnométodos em interação, entendidos como formando uma unidade ou, nos termos de Gurwitsch (1964) e Garfinkel (2002), uma gestalt contextual, e, para Mondada (2014), uma gestalt multimodal ${ }^{7}$, que dá conta de uma análise que se propõe a responder ao questionamento que tanto norteou o precursor dos estudos interacionais, Harvey Sacks: “por que isso agora?” (CRUZ et al., 2019).

\footnotetext{
${ }^{7}$ Nas palavras de Mondada (2014, p. 139), gestalt multimodal consiste em "[...] uma rede de recursos que formam uma ação".
} 
Os dados analisados neste artigo advêm da gravação em áudio e/ou vídeo ${ }^{8}$ de dez interrogatórios policiais que aconteceram entre abril de 2017 e janeiro de 2018 em três Delegacias de Polícia Civil do Estado do Rio Grande do Sul, Brasil. O conjunto de dados também integra notas de campo realizadas ao longo das observações dos interrogatórios policiais gravados. ${ }^{9}$

A transcrição das interações foi realizada com base nas convenções (listadas no Anexo 1) propostas por Jefferson (1984) e adaptadas pelo Grupo de Pesquisa Fala-emInteração em Contextos Institucionais e Não Institucionais, com base em algumas sugestões do grupo GAT2 ${ }^{10}$ (SELTING et al., 2011). Para as condutas corporificadas (como gestos, direcionamento de olhar, etc.) registradas em vídeo e que se mostram interacionalmente relevantes para os participantes, usaram-se as convenções propostas por Mondada (2018), e apresentadas, resumidamente, no Anexo 2. Nomes originais dos participantes das interações foram substituídos, nas transcrições, por pseudônimos, para fins de anonimização.

\section{6 "NÃO TÔ LEMBRADO DE TÊ COMPRADO": O RESGUARDO DE INFORMAÇÕES REALIZADO POR INTERROGADOS}

Nesta seção, discutem-se sequências interacionais em que os interrogados, em seus turnos responsivos, não desempenham as ações tornadas relevantes nas perguntas feitas pelos policiais. Em vez disso, suas ações em resposta consistem predominantemente em declarações de deslembrança ou dessaber em relação aos fatos do crime. Tais declarações, coordenadas com outros etnométodos (como condutas corporificadas e provimento de justificativas) empregados pelos interrogados ao longo das interações, acabam por resguardar informações acerca das infrações sob investigação.

$\mathrm{O}$ primeiro fragmento de fala que integra a análise contempla um interrogatório do qual participam os policiais Pablo (POL1) e Manuel (POL2), e o interrogado Júlio (INT), acusado pelo crime de estelionato. Segundo as investigações, o INT teria comprado uma arma de pressão com um cheque falso. O Excerto 1 acontece no início do interrogatório. É necessário esclarecer que as imagens que o POL1 mostra para o INT se referem a capturas de vídeo do suposto acusado realizando a compra da arma. Trata-se de imagens da câmera de segurança do estabelecimento onde o crime acontecera.

${ }^{8}$ Os dados foram gravados em áudio e/ou vídeo de forma a alargar as opções aos participantes de autorizarem apenas áudio, se assim desejassem - além de, certamente, também optarem por não participarem de todo.

9 Faz-se necessário explicitar que todas as interações observadas e gravadas aconteceram após o consentimento oral e escrito dos participantes por meio da assinatura do Termo de Consentimento Livre e Esclarecido, homologado pelo Comitê de Ética em Pesquisa da Universidade do Vale do Rio dos Sinos/Unisinos. Certificado de Apresentação para Apreciação Ética: 66007617.9.0000.5344. Número do parecer consubstanciado: 2.031.426.

${ }^{10}$ GAT é o acrônimo de "Gesprächsanalytisches Transkriptionssystem" (Sistema de Transcrição de Análise da Conversa e do Discurso). 
Excerto 1: DP_pablo_manuel_JÚLIO_11_05_2017

\begin{tabular}{|c|c|c|}
\hline 03 & POL1: & $\begin{array}{l}\text { é tu >ou } \uparrow \text { não< ((mostra, p/ o INT, imagens } \\
\text { contidas no inquérito policial)) } \\
(5.8) \text { ((INT olha p/ as imagens no documento)) }\end{array}$ \\
\hline 05 & POL1: & $\begin{array}{l}\text { melhor é: já: : v- que é é } \downarrow \text { né } \\
(0.8)\end{array}$ \\
\hline 06 & INT: & $\{\{$ agudo $\}$ não\} be:m bem pa[recido $\uparrow$ né $]$ \\
\hline 07 & POL1: & [é: não: : ] v: :- é ou \\
\hline 08 & & $\begin{array}{l}\text { não } \uparrow e ́ \\
(1.3) \quad((\text { INT pigarreia }))\end{array}$ \\
\hline 10 & INT : & $\begin{array}{l}\text { n:ão tô lembrado de tê comprado } \\
(8.7) \quad((\text { INT tosse }))\end{array}$ \\
\hline 12 & POL2: & tu tem teu: : documento \\
\hline 13 & & aí: [: : e (†te) \\
\hline 14 & POL1: & [tu qué- tu vai] fazê $a$ aí \\
\hline
\end{tabular}

Fonte: Transcrito pelas autoras.

O POL1, ao mostrar para o INT imagens supostamente suas quando teria realizado o crime de estelionato, pede-lhe uma informação: é tu >ou $\uparrow$ não<. Porém, como se pode observar, o INT não toma o próximo turno, não se alinhando, assim, ao curso de ação implementado pelo POL1. Esse não alinhamento, contudo, pode ser justificado pelo fato de o INT estar orientado visualmente para as imagens contidas no inquérito policial (linha 03). O POL1, então, toma o turno novamente na linha 04, iniciando-o com um provável conselho ao INT (melhor é: já: : : v-). Ao que tudo indica, na continuidade do turno, o POL1 sugeriria ao INT que o melhor a fazer seria admitir-se, já no início do interrogatório, como a pessoa que se vê nas imagens e, portanto, como o autor do estelionato. No entanto, verifica-se que o POL1 interrompe a trajetória de seu turno, de forma a revisá-lo. Ou seja, abandona a ação de "sugerir" para, em vez disso, pedir por confirmação: que é é $\downarrow$ né. Observa-se, aqui, que esse pedido de confirmação é realizado como quase uma afirmação, tendo em vista seu formato prosódico plano, seguindo da partícula "né" em entonação descendente.

Depois de quase um segundo, observa-se que o INT não confirma e nem desconfirma o que fora solicitado pelo POL1, produzindo uma resposta não conformativa: $\{\{$ agudo\} não\} be:m bem pa[recido $\uparrow$ né]. Na composição do turno responsivo, o "não", na verdade, não nega. Em vez disso, é usado como um marcador disjuntivo que, de certa forma, afilia-se a algo que está proposto na pergunta do POL1. Ou seja, o INT reconhece que a pessoa apresentada nas imagens se assemelha a ele. Assim, o acusado reconhece que o POL1 teria alguma razão em acreditar que ele (INT) é a pessoa que aparece nas imagens da compra da arma. Ademais, apesar de não confirmar ser ele, o INT também não nega (ou desconfirma). Com essa ação responsiva, o INT resiste embarcar no curso de ação implementado pelo POL1. 
Essa prática é capaz de evidenciar a "competência-em-ação" do acusado ao não se responsabilizar pelo fornecimento de uma (des)confirmação: se confirmasse, por exemplo, que a pessoa das imagens é ele, o INT estaria admitindo o crime. Por outro lado, se simplesmente insistisse não ser ele, o INT estaria disputando o "óbvio", já que as imagens do vídeo revelam um sujeito que, no mínimo, apresenta grande semelhança física com ele. Assim, ao admitir que a pessoa presente nas imagens é "bem parecida" com ele, o INT consegue, de certa forma, driblar as evidências, provendo uma resposta verossímil e pela qual não pode ser imputado por desonestidade. Reconhecer que a pessoa que se vê na imagem é "bem parecida" com ele é, portanto, uma maneira de o INT não confirmar nem desconfirmar a acusação que lhe é atribuída - e, ainda, de se eximir dela.

Dando continuidade à análise sequencial, antes mesmo de o INT concluir seu turno de fala (linha 06), o POL1, possivelmente orientado para o não recebimento de uma confirmação ou de uma desconfirmação, toma o turno em sobreposição, de forma a desafiar o INT, pedindo-lhe uma informação equivalente àquela solicitada inicialmente ([é: não: :] v: :- é ou não †é). Trata-se de uma forma de o POL1 "colocar o INT contra a parede", uma vez que busca, em nova tentativa, obter uma resposta que, de fato, responda àquilo que fora solicitado. Em outras palavras, o POL1 "resiste à resistência" exercida na resposta do INT. Observa-se que, até o INT tomar o turno, há uma ausência de fala de um segundo e três décimos, durante a qual o INT pigarreia. Esses elementos que precedem a resposta do INT (atraso na resposta e pigarreio) caracterizam despreferência e acabam por postergar o turno responsivo. Ao responder, observa-se que o INT provê uma resposta cuja ação e formato são despreferidos, pois não atendem àqueles tornados relevantes na pergunta: $\mathrm{n}$ :ão tô lembrado de tê comprado (linha 10). Como se pode observar, o INT não provê a informação solicitada - um sim ou um não - não atendendo à lógica binária das perguntas polares (LYNCH; BOGEN, 2005).

Ao declarar "não estar lembrado" de ter comprado a arma de pressão, o INT, mais uma vez, mostra sua competência interacional: veja-se que "não estar lembrado" difere significativamente de "ter esquecido". Quando uma pessoa declara esquecimento (e.g., "eu esqueci de lhe telefonar"), ela pressupõe um conhecimento retrospecto daquilo que fora esquecido. No momento em que o INT alega deslembrança, ele deixa de reconhecer a existência de um evento passado (LYNCH; BOGEN, 2005). Assim, as escolhas lexicais de seu turno de fala responsivo operam de maneira a lhe desvincular de um evento passado que envolva a compra de uma arma. Isso porque a declaração de deslembrança acaba por consistir em um etnométodo empregado pelo INT para "sair pela tangente" inimputável, uma vez que o uso do verbo "lembrar", em sua forma negativa, é também uma maneira de não mentir; a "deslembrança" não é algo disputável. Além disso, se o INT respondesse que a pessoa das imagens não é ele, essa informação poderia ser passível de discussão, considerando que a polícia dispunha de imagens da ação do crime.

Há de se considerar, contudo, que existem fatos dos quais se espera que as pessoas se lembrem (COULTER, 1979). Comprar uma arma de pressão no valor de R \$2.000,00 é, definitivamente, um deles. Comprar uma arma não é uma atividade que se equipara a uma prática cotidiana como a de comprar pão, por exemplo; ainda mais para uma pessoa cuja atividade profissional não tenha nenhuma relação com o uso de armas. Apesar disso, percebe-se, na continuidade do Excerto 1, que o POL1 não expande a sequência interacional, não problematizando essa e/ou outras questões. 
O Excerto 2, a seguir discutido, compreende uma interação entre o policial Pablo (POL) e um interrogado acusado de uma tentativa de homicídio, André (INT), e acontece na metade do interrogatório. Para que se compreenda o segmento, cabe mencionar que, de acordo com as investigações, o crime, que acontecera em uma danceteria, fora cometido por duas pessoas, e suspeita-se que o outro infrator seja um primo de André, chamado Alexandre.

\section{Excerto 2: DP_pablo_ANDRÉ_02_05_2017}

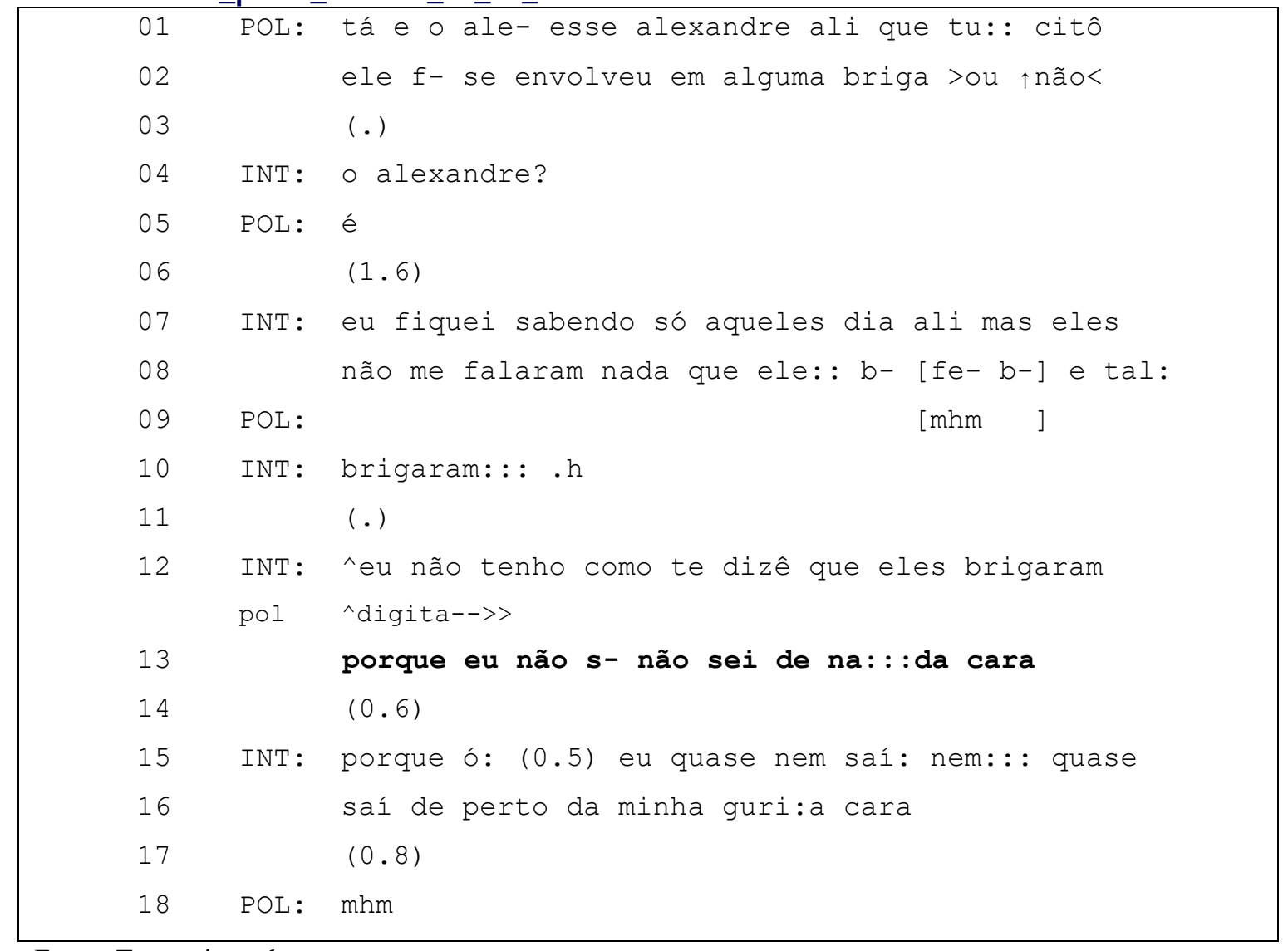

Fonte: Transcrito pelas autoras.

Ao longo das linhas 01-02, o POL pede uma informação ao INT: tá e o aleesse alexandre ali que tu: : citô ele f- se envolveu em alguma briga >ou $\uparrow$ não<. Trata-se de uma pergunta relativa ao primo do INT, Alexandre. Como se pode observar, o INT toma o turno depois de uma micropausa, mas não provê a informação solicitada na pergunta do POL. Em vez disso, ele quebra a progressividade da interação (SACKS, 1987) por meio de uma iniciação de reparo ${ }^{11}$ : a lexandre? Especula-se que essa iniciação de reparo não se refira a algum problema de audição ou de entendimento por parte do INT em relação à pergunta do POL - isso porque, nas linhas que antecedem o Excerto 2, os interagentes já estavam falando sobre Alexandre, e nenhum outro primo do acusado fora mencionado. Ao usar de seu turno responsivo com uma iniciação de

\footnotetext{
${ }^{11}$ Reparos acontecem para lidar com problemas ou mal-entendidos da ordem da produção da fala, da audição ou do entendimento.
} 
reparo por meio de uma pergunta (“o Alexandre?”), o interrogado parece resistir à restrição imposta pela pergunta (BOLDEN, 2009) do policial investigador - cuja resposta tornada relevante seria simplesmente um "sim" ou um "não". Com essa ação, o INT acaba por adiar ou mesmo evadir-se da resposta buscada (BOLDEN, 2009), repercutindo, inclusive, em mais tempo para elaborar uma resposta à pergunta inicial do policial.

Depois de o POL confirmar (“é"), passa-se um pouco mais de um segundo e meio até que o INT tome o turno. Um segundo e meio consiste em uma duração considerada longa entre uma primeira e uma segunda parte de um par adjacente ${ }^{12}$, o que acarreta, de fato, mais tempo para o acusado prover uma resposta: eu fiquei sabendo só aqueles dia ali mas eles não me falaram nada que ele: brigaram: : : . h. Observe-se que o INT não fornece a informação solicitada pelo POL. Em vez disso, produz uma espécie de justificativa por não fornecê-la, marcada por disfluências, tais como alongamento de sons, interrupções abruptas de fala, autorreparos e inspiração audível, elementos que revelam alguma dificuldade ou problema de outra natureza na produção da informação solicitada. Também se sabe que "aqueles dia ali" refere-se a uma data posterior à do crime, já que, conforme relatado pelo próprio INT, ele soubera de sua acusação quando estava em uma festa ocorrida posteriormente à data do crime. Apesar de ter ficado sabendo de sua própria acusação, o INT torna explícito que não fora informado de uma briga na qual seu primo estivera envolvido.

Observa-se também que, depois de uma micropausa, o INT formula "com todas as letras" a impossibilidade de prover a informação (eu não tenho como te dizê que eles brigaram) e provê uma outra justificativa para isso (porque eu não s- não sei de na: : :da cara). Mais uma vez, a justificativa é produzida com disfluências típicas de desprerência (interrupção de fala, repetição de palavras e alongamento de som).

Disso resulta que, ao declarar-se desconhecedor daquilo que fora perguntado, o INT acaba provendo uma justificativa inimputável, uma vez que também aqui ele nega saber (eu não s- não sei de na: : :da cara). De modo geral, não há meios de comprovar que o INT não sabe de nada. Ainda assim, trata-se de uma maneira de ele evitar se comprometer com o provimento de uma informação capaz de lhe imputar culpa, ou ao seu primo. Nas palavras da linguista interacional Leelo Keevallik (2016), uma declaração de desconhecimento como a realizada aqui pelo INT pode consistir em uma estratégia de reestabelecimento de um "beco sem saída" anteriormente ocasionado na interação. No caso do Excerto 2, o "beco sem saída" é claramente provocado pelo pedido de informação realizado pelo POL nas linhas 01-02, atribuindo ao INT o status de epistêmico (HERITAGE, 2012) de conhecedor sobre o que está sendo perguntado.

Na continuidade da interação, após seis décimos de segundo, o INT, possivelmente orientado para o fato de o POL não ter se alinhado verbalmente à sua justificativa (todavia, atento para o fato de o POL estar realizando a ação de digitação), e/ou por reconhecer não ter fornecido uma justificativa credível ao POL, provê detalhes da justificativa: porque ó: (0.5) eu quase nem saí: nem: : q quase saí de perto da minha guri:a cara. Esse turno é também produzido com disfluências típicas de despreferência: pausa, repetição de palavras e alongamento de sons. Enfatiza-se que, ao prover essa justificativa, o INT se remete ao dia e ao local do crime, uma vez que, no

\footnotetext{
${ }^{12}$ A duração média em termos de espaço de transição entre falantes é, de acordo com Schegloff (2000), um intervalo que varia entre 150 e 250 milésimos de segundo.
} 
início da interação, ele já havia informado ao POL que estivera a maior parte do tempo com a sua companheira. Por meio dessa justificativa, além de prover uma possível explicação por não ter "visto nada demais" na festa e, consequentemente, favorecer a condição de seu primo (também acusado pelo mesmo crime), o INT acaba por se desengajar de uma provável aproximação em relação ao delito.

Assim, a análise dos Excertos 1 e 2 revela uma das formas com que os interrogados, em suas respostas, não atendem ao que é tornado relevante nas perguntas dos policiais. Em ambos, há um desengajamento explícito por parte dos acusados nas respostas às perguntas que oferecem alternativa binária ("sim" ou "não"). Essa não conformidade em relação às perguntas, que acaba por não atender ao que é solicitado aos acusados (i.e., não provimento da informação solicitada), é ocasionada pela declaração de dessaber e de deslembrança, dentre outros etnométodos empregados pelos interrogados, que operam em favor do resguardo dos fatos dos crimes sob investigação e, portanto, em favor da construção de sua própria inculpabilidade.

\section{7 "TU SABE MAIS OU MENOS QUE HORAS FOI?": O RESGUARDO DE INFORMAÇÕES OPORTUNIZADO POR POLICIAIS}

Que em um interrogatório um suspeito busque resguardar determinadas informações acerca de um crime pelo qual é acusado na forma como responde não é novidade. Os dados aqui analisados, contudo, mostram outra forma de resguardo, ainda não descrita na literatura. Trata-se do resguardo que é oportunizado pelos próprios policiais no formato das perguntas que fazem para buscar informações.

Os participantes do Excerto 3, analisado a seguir, são o policial Ricardo (POL) e o interrogado Renan (INT), acusado de homicídio doloso. Na transcrição dos gestos dos interagentes, o símbolo de acento circunflexo $\left(^{\wedge}\right)$ refere-se às condutas corporificadas do POL, ao passo que o símbolo de asterisco $(*)$, às do $\mathrm{INT}^{13}$. Para fins de contextualização, faz-se necessário explicar que, em momentos anteriores ao fragmento apresentado a seguir, o INT informa que, embora estivesse dormindo no momento do crime pelo qual está sendo acusado, teria escutado tiros próximos à sua residência.

\section{Excerto 3: DP_ricardo_RENAN_05_01_2018}

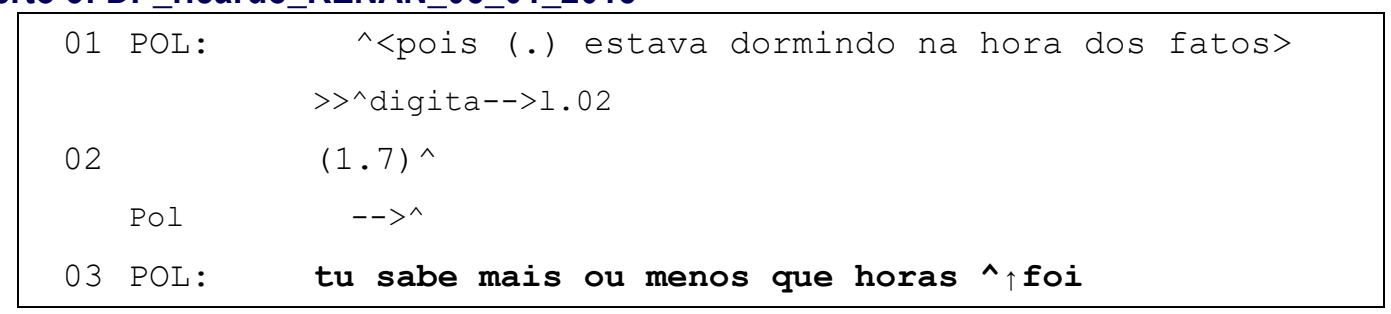

13 Torna-se essencial explicar que, na transcrição multimodal, a linha destinada à representação das condutas corporificadas dos interagentes é inserida imediatamente após o turno de fala no qual tais condutas estão incorporadas, o que, obviamente, não significa uma segmentação entre conduta verbal e não verbal. Pelo contrário, essa é uma forma de mostrar a temporalidade e coordenação de um tipo de conduta em relação à outra. Ou seja, é justamente esse sistema de transcrição multimodal (MONDADA, 2018) que, até o presente momento, apresenta-se como o mais adequado para a representação da temporalidade exata em que os elementos não verbais acontecem em coordenação com a fala dos participantes. 


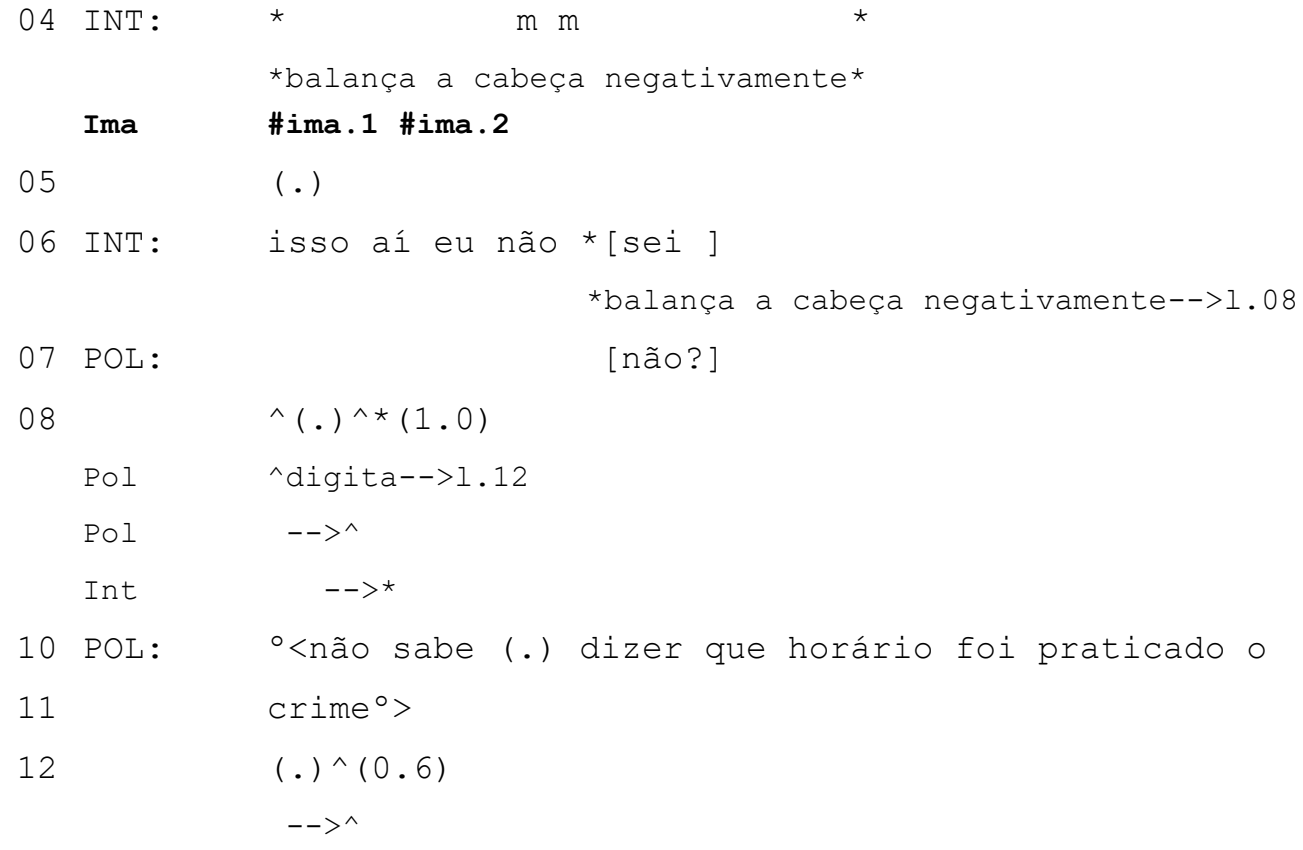

Fonte: Transcrito pelas autoras.

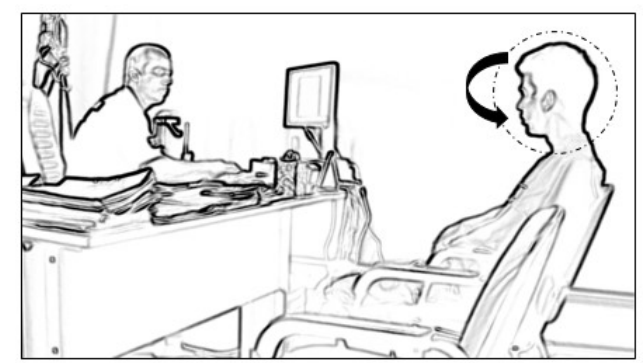

\#Ima.1

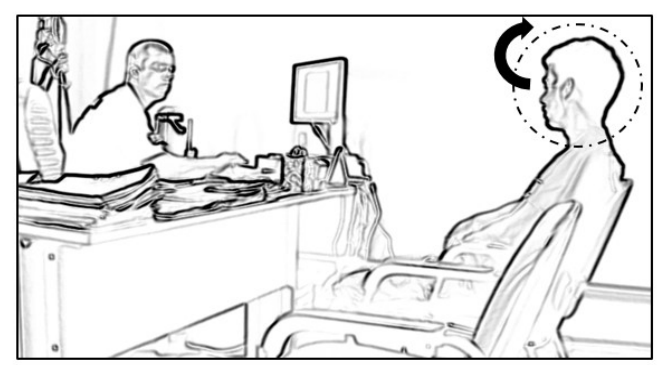

\#Ima.2

\section{Figura 1 - Captura de vídeo das Imagens do Excerto 3}

Fonte: Elaborada pelas autoras com base nos registros de vídeo.

Na linha 01, o POL lê em voz alta o que está digitando (informações fornecidas anteriormente pelo INT). Ao finalizar esse registro, o POL pede uma nova informação ao acusado: tu sabe mais ou menos que horas $\uparrow$ foi (linha 03). Chama-se a atenção para a composição dessa pergunta. Ora, essa informação poderia ter sido solicitada de forma mais direta, como por exemplo, "a que horas foi X?" ou mesmo "a que horas mais ou menos foi X?". Contudo, o pedido da informação é feito em formato diferenciado, com o uso de duas orações, sendo a primeira delas "tu sabe". Ao utilizar-se do "saber", que gera um enunciado com duas orações, "(1) tu sabe (2) que horas foi", o POL oportuniza que o INT opte por responder apenas à primeira das duas partes, declarando, dessa forma, "não saber" a informação requerida, sem que essa ação seja tomada como algum tipo de resistência em colaborar com o POL. 
Ou seja, o resguardo das informações, em vez de acontecer de forma unilateral, como se viu nos Excertos 1 e 2, aqui, acontece de forma colaborativa entre o POL e o INT. Isso porque, quando o investigador "oferece" ao INT a possibilidade de saber ou não, ele justamente oportuniza que o INT se alinhe imediatamente à primeira oração, declarando falta de acesso epistêmico no que concerne à informação solicitada: $\mathrm{m} \mathrm{m} \mathrm{/}$ isso aí eu não [sei]. Observa-se, ainda, que a negação do acesso epistêmico sobre a informação relacionada ao horário do crime por parte do INT acontece de forma coordenada entre a conduta verbal ("m m") e a corporificada (o acusado balança a cabeça negativamente, como se pode visualizar na Figura 1). Por meio dessa ação multimodal, o INT nega acesso epistêmico sobre a hora do crime.

O resguardo das informações acerca do crime oportunizado pelo POL (ao perguntar se o INT "sabe", transformando uma pergunta em duas orações, em vez de perguntar-lhe diretamente a hora), resulta em uma resposta que acaba por não oferecer resistência alguma ao que fora solicitado. Pelo contrário, ao responder de maneira negativa, o INT atende justamente de forma conformativa (e sem resistência) ao que é mobilizado pelo POL. Dito de outra forma, o resguardo é, não apenas oportunizado, mas também iniciado pelo próprio POL.

Observa-se, também, que o formato da pergunta realizada pelo POL gera consequências para o desenrolar da sequencialidade interacional com um todo. É de comum entendimento que o interagente que pergunta possui controle sobre a conversa. Entretanto, como explica Sacks (1992), essa regra, apesar de prevalecer interacionalmente, não se aplica a todos os casos. É o que acontece no Excerto 3. Ao perguntar "tu sabe mais ou menos que horas foi?", o policial investigador permite, na estrutura de sua pergunta, a possibilidade de o interrogado abandonar o curso de ação por ela iniciado, de maneira a evadir-se desse tópico (horário do crime) o mais rápido possível. O policial, ao "facilitar", já na pergunta, o provimento da ação solicitada, acaba por também oportunizar que a sequência termine ali, evitando, assim, outras possíveis expansões da sequência que poderiam gerar informações importantes acerca do crime. Não há, por exemplo, mais o que se perguntar sobre o "horário do crime", assim, o POL perde, de certa forma, o direito ou, minimamente, a oportunidade sequencial, de realizar qualquer outra pergunta referente a esse mesmo tópico. Explicado de outra forma, não há dúvidas que uma resposta é construída tendo em vista o projeto de sua pergunta (SACKS, 1992). E, como já mencionado, um turno de fala responsivo equivalente a "não sei" para perguntas do tipo “Tu sabe X...?” ou "Tu sabe se X...?” e perguntas iniciadas por "Que X...?" ou "Foi X...?" gera diferentes desdobramentos interacionais.

Exemplificamos a partir da comparação dos recortes a seguir.

\section{Excerto 4: Recorte do Excerto 3}

\begin{tabular}{|c|c|c|c|c|}
\hline \multirow{2}{*}{\multicolumn{2}{|c|}{03 POL: }} & \multicolumn{2}{|c|}{ tu sabe mais ou menos que horas } & $\wedge_{\uparrow}$ foi \\
\hline & & & & ^olha p/ INT-->1.08 \\
\hline 04 & INT: & $\mathrm{m} \mathrm{m}$ & * & \\
\hline & & \multicolumn{3}{|c|}{ *balança a cabeça negativamente* } \\
\hline 05 & & $()$. & & \\
\hline
\end{tabular}




\section{INT: isso aí eu não *[sei ]}

*balança a cabeça negativamente-->l.08

Fonte: Transcrito pelas autoras.

\section{Excerto 5: Recorte do Excerto 1}

\begin{tabular}{|lcl|}
\hline 07 & POL1: & [é: não: $]$ v: $:$ é ou \\
08 & não $\uparrow$ é \\
09 & $(1.3) \quad(($ INT pigarreia $))$ \\
10 & INT: & $\mathbf{n}:$ ão tô lembrado de tê comprado
\end{tabular}

Fonte: Transcrito pelas autoras.

Observa-se que, no Excerto 4, a declaração de dessaber, isso aí eu não sei (linha 06), é conformativa ao formato e à ação tornados relevantes na pergunta do POL (linha 03): tu sabe mais ou menos que horas foi? (grifo nosso). Contudo, no Excerto 5, a declaração de deslembrança do INT, $\mathrm{n}$ :ão tô lembrado de tê comprado (grifo nosso), mostra-se não conformativa, resistindo à ação e ao formato tornados relevantes na pergunta, que pedia por um "sim" ou um "não" (é ou não †é ).

$\mathrm{O}$ que se vê acontecer no Excerto 3 é que o resguardo das informações acerca do crime, quando oportunizado pelo POL na interação, revela-se, em certa medida, favorável ao INT, já que ele não mais precisa resistir à ação e ao formato tornados relevantes na pergunta do POL. Pelo contrário. Basta que se alinhe à ação de resguardar os fatos, iniciada e oportunizada por POL.

É importante salientar aqui que o que se percebe no Excerto 3 não é ocasional. É uma prática recorrente nos dados, que será também vista no Excerto 6, discutido a seguir, e do qual participam o policial Pablo (POL) e um interrogado acusado de agressão física, Vilson (INT). O INT responde também por posse e tráfico de drogas; entretanto, no excerto a seguir, que corresponde ao meio do interrogatório, ele está sendo interrogado pelo crime de agressão física. Na transcrição, o símbolo de acento circunflexo $\left(^{\wedge}\right)$ remete às condutas corporificadas do POL, enquanto que o símbolo de asterisco (*) alude às do INT.

\section{Excerto 6: DP_pablo_VILSON_01_06_2017}

$\begin{array}{lll}01 & \text { INT: } & \text { e daí foi onde que eu consegui pegá os guri e: } \\ 02 & & (0.8) \text { levei pra casa e bati } \\ 03 \text { POL: } & \text { tá } \\ 04 & (.) & \\ 05 \text { POL: } & \text { ontão ^vamo vê } \\ 06 & \\ & \end{array}$




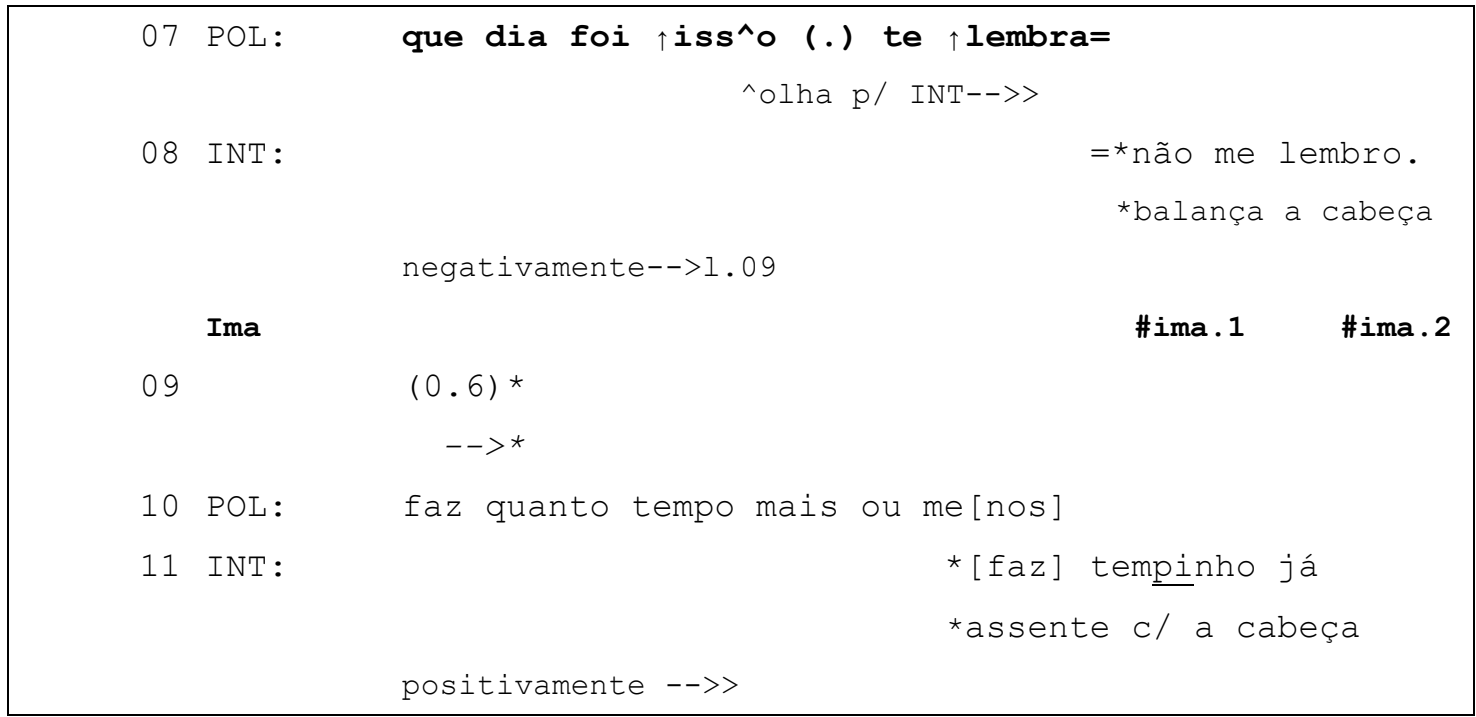

Fonte: Transcrito pelas autoras.

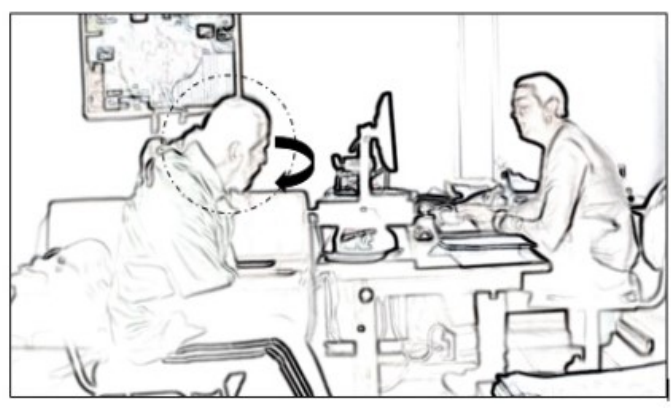

\#Ima.1

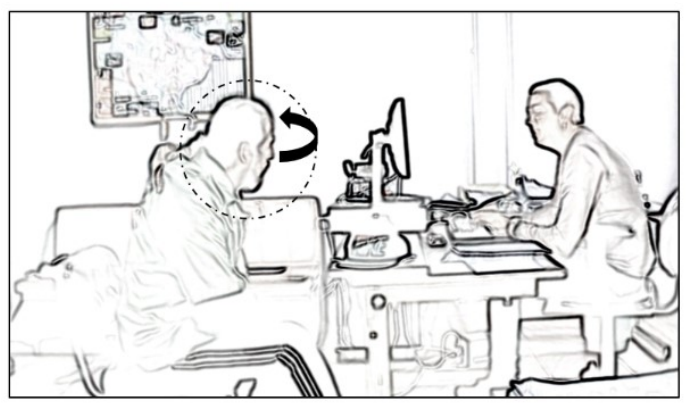

\#Ima.2

Figura 2 - Captura de vídeo das Imagens do Excerto 6

Fonte: Elaborada pelas autoras com base nos registros de vídeo.

Nas linhas 01-02, o INT está terminando um relato concernente aos fatos que culminaram no crime de agressão física. Até esse momento, o POL ainda não havia digitado nenhuma informação sobre esse crime no Termo de Interrogatório. Assim que assinala o recebimento das informações fornecidas pelo INT (tá), o POL, ao produzir - então vamo vê e aproximar sua cadeira do computador, anuncia a necessidade de registrar essas e outras informações sobre o fato em questão. Como se pode observar, o POL, então, começa a inquirir o INT.

Na linha 07, o POL pede ao INT a informação sobre o dia do crime em questão: que dia foi $\uparrow$ isso (.) te $\uparrow$ lembra. Observa-se que, para pedir essa informação, o POL desenha seu turno com duas perguntas, sendo que a primeira delas (que dia foi $\uparrow$ isso) já seria suficiente para mobilizar uma resposta por parte do INT.

De forma muito semelhante ao que vimos acontecer na interação no trem apresentada no início deste artigo, ao perguntar te $\uparrow$ lembra, o POL acaba por oportunizar o não provimento da informação e, assim, por possibilitar que o INT declare 
deslembrança em relação ao que está sendo perguntado. É o que de fato acontece: o INT, sem demora, responde e se alinha, seguindo também o princípio de contiguidade interacional (SACKS, 1987), com a segunda das duas orações, ao declarar não me lembro, enquanto balança a cabeça negativamente (Figura 2). Assim como no excerto anterior, a conduta não verbal representa a concretude da ação de declaração de falta de acesso epistêmico do INT concernente à data do crime.

Assim como se viu no Excerto 3, também aqui, ao produzir a segunda pergunta no formato polar com o verbo "lembrar" (te $\uparrow$ lembra), o POL vai de encontro a uma das finalidades principais do próprio interrogatório - a apuração de informações sobre o crime -, ao oportunizar que o INT resguarde os fatos. Tivesse o POL produzido apenas a primeira pergunta para realizar o pedido de informação, a resposta de "não se lembrar" poderia ser provida pelo próprio INT. Ou seja, responder com "não me lembro" a uma pergunta que pede "que dia foi isso" gera consequências distintas para a interação, uma vez que a declaração de deslembrança opera como resistência. Já uma resposta de "não me lembro" a uma solicitação que oportuniza a deslembrança (“te lembra?") é justamente conformativa e alinhada à pergunta.

Como se pode observar na continuidade da interação, na linha 10, o POL pede outra informação (faz quanto tempo mais ou me [nos]) por meio de uma pergunta aberta (que integra um pronome interrogativo: "quanto") cuja composição não envolve a seleção de formatos que oportunizem resguardo de fatos do crime. Apesar de ser com inexatidão, INT provê uma informação ( [ faz ] tempinho já) em vez de declarar deslembrança ou dessaber. A eficácia dessa pequena sequência específica de pergunta-resposta (linhas 1011), diferentemente da anterior (linhas 07-08), opera de forma a corroborar os propósitos práticos de inquirição do interrogatório policial. Observa-se, aqui, que a estrutura da pergunta do policial (faz quanto tempo mais ou me [nos]) não tende a estagnar a busca pela verdade dos fatos. Veja-se que se a problematização do tópico "data do crime" fosse circunscrita ao par adjacente pergunta-resposta das linhas 07-08 (que dia foi

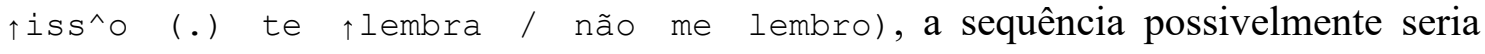
abandonada.

A análise dos Excertos 3 e 6, portanto, evidencia que, diante de todas as possibilidades de perguntas que um policial pode realizar para buscar os fatos do crime, o formato "tu (você) sabe/lembra X" em pedidos de informações aos INT possibilita que os acusados resguardem informações de relevância para a investigação. Em outras palavras, ao pedirem informações por meio de perguntas com a seleção lexical de verbos como "saber" e "lembrar", os policiais viabilizam o fornecimento de respostas que provejam declarações de dessaber ou de deslembrança sem qualquer resistência por parte dos interrogados. Pelo contrário, são respostas conformativas, alinhadas e afiliativas e que, de certo modo, não são condutivas à progressividade do assunto. 
$\mathrm{Na}$ introdução deste artigo, viu-se, a partir de duas narrativas trazidas por Sacks (1992), que sequências de perguntas e respostas culminam em consequências capazes de estagnar ou não o curso de ações iniciado por meio de perguntas. Os desdobramentos do resguardo de informações acerca dos crimes analisados ao longo deste artigo corroboram as implicações interacionais exploradas na seção introdutória deste estudo. Quando o resguardo dos fatos é realizado pelos interrogados, observa-se sua agentividade ao resistir ao provimento das informações e/ou confirmações solicitadas nas perguntas dos policiais. Sua resistência acontece por meio de respostas não conformativas, e cujas ações consistem em declaração de dessaber, deslembrança ou desconhecimento, bem como em provimento de justificativas e/ou de outras informações. Tais respostas, capazes de interromper o curso de ações implementado pelas perguntas e, portanto, estagnar a sequência interacional, acabam por gerar desobrigação dos interrogados de acesso epistêmico sobre determinadas informações acerca dos crimes, eximindo-lhes, por vezes, da própria imputação a eles atribuída.

No resguardo de informações acerca dos crimes "oferecido" pelos próprios policiais, observa-se que as perguntas são realizadas em formatos de duas orações, sendo que uma delas envolve "saber" ou "lembrar". Ao perguntarem se os interrogados "sabem" ou "lembram" de alguma informação referente ao fato ocorrido, os investigadores acabam por oportunizar que os interrogados declarem dessaber e/ou deslembrança em relação ao crime sob acusação. O formato de duas orações nas perguntas dos investigadores propicia a descontinuação (não problemática) da sequência interacional que envolve o tópico perguntado.

Como se pôde observar nos dados, as perguntas descritas no parágrafo acima geram respostas conformativas, alinhadas e afiliativas, ajustando-se sem a necessidade de qualquer resistência ao que é tornado relevante nas perguntas dos policiais: não lembrar e não saber. Ou seja, as informações relativas aos crimes investigados são, portanto, resguardadas sem que os interrogados ofereçam resistência em suas respostas.

Tendo em vista essas duas práticas de resguardo de informações acerca dos crimes - uma delas, em formato de resistência, em segunda posição, e realizada unilateralmente pelos interrogados; a outra, em formato conformativo e afiliativo, também realizada em segunda posição, mas iniciada e oportunizada pelo policial já em primeira posição (no turno em que pergunta), fazem-se as seguintes considerações: entende-se que a primeira das duas práticas é certamente inevitável, uma vez que os acusados têm livre arbítrio no provimento de suas respostas. Contudo, a segunda delas - o resguardo oportunizado nas perguntas dos policiais -, ainda que também de livre arbítrio, pode, em princípio, ser evitada ou, minimamente, controlada em sua frequência, visto que os investigadores, no Brasil, têm autonomia na escolha dos elementos composicionais de suas perguntas, desde que, ao interrogarem, não deixem, obviamente, de respeitar a Lei.

Os achados provenientes da análise do corpus que integra este estudo ratificam o que é explicitado na introdução deste artigo: que é no aqui-e-agora interacional que a prática de interrogar se efetiva. Ora, se a maneira como cada policial interroga e emprega 
reflexivamente as regras pertencentes ao estatuto local da Delegacia de Polícia resulta das interações, entende-se que é a partir das interações que se encontram respostas sobre "como interrogar". Se, por exemplo, os investigadores tivessem acesso às consequências interacionais geradas pelas perguntas que oportunizam o resguardo dos fatos dos crimes, poderiam refletir sobre as suas próprias práticas de interrogar; práticas essas, capazes de propiciar outras trajetórias interacionais e, quem sabe, até mesmo outros desfechos às investigações policiais.

\section{AGRADECIMENTOS}

Agradecemos ao CNPq pelo auxílio à pesquisa com Bolsa de Produtividade em Pesquisa concedida à segunda autora (Processo no: 309351/2016-2).

Agradecemos aos/às pareceristas as leituras atentas e sugestões qualificadas.

\section{REFERÊNCIAS}

ANDRADE, D. N. P.; OSTERMANN, A. C. O interrogatório policial no Brasil: a fala institucional permeada por marcas de conversa espontânea. Calidoscópio, São Leopoldo, v. 5, n. 2, p. 92-104, 2007. ANDRIOLI, F.; OSTERMANN, A. C. Entendendo o entendimento em aulas de língua inglesa: uma perspectiva interacional multimodal. Acta Scientiarum, Maringá, v. 41, p. 1-14, 2019.

BITTNER, E. Grant Proposal: The Harold Garfinkel Archives, Newberryport, MA. BITTNER, E. Larimer Tours, Ethnographic Studies n. 13/2013, p. 123-174, [1965] 2013.

BOLDEN, G, B. Beyond answering: Repeat-prefaced responses in conversation, Communication Monographs, v. 76, n. 2, p. 121-143, 2019.

BRASIL. Lei $n^{\circ}$ 10.792, de 1 de janeiro de 2003. Altera A Lei no 7.210, de 11 de Junho de 1984 - Lei de Execução Penal e O Decreto-lei no 3.689, de 3 de Outubro de 1941 - Código de Processo Penal e Dá Outras Providências. Disponível em: <http://www.planalto.gov.br/ccivil_03/leis/2003/L10.792.htm>. Acesso em: 3 jan. 2019.

CLIFT, R. Conversation Analysis. Cambridge: Cambridge University Press, 2016.

COSTA, S. P. T. S.; CUNHA, M. A. F. A construção com verbos de cognição no português brasileiro: um estudo preliminar. Gragoatá, Niterói, n. 40, p. 250-272, 2016.

COULTER, J. Transparency of Mind: the Availability of Subjective Phenomena In: COULTER, J. The Social Construction of Mind: Studies in ethnomethodology and linguistic philosophy. London: Macmillan, 1979. p. 35-62.

CRUZ, F. M.; OSTERMANN, A. C.; ANDRADE, D. P. N.; FREZZA, M. O trabalho técnicometodológico e analítico com dados interacionais audiovisuais: a disponibilidade de recursos multimodais nas interações. D.E.L.T.A., v. 35, n. 4, p. 1-36, 2019.

DREW, P. Turn Design. In: SIDNELL, J.; STIVERS, T. (Eds.) The Handbook of Conversation Analysis. Chichester, UK: Wiley-Blackwell, 2013. p. 131-149.

GARFINKEL, H. Studies in ethnomethodology. Englewood Cliffs, New Jersey, Prentice-Hall Inc, 1967.

GARFINKEL, H. An Ethnomethodological Study of the Work of Galileo's Inclined Plane Demonstration of the Real Motion of Free Falling Bodies. In: GARFINKEL, H.; RAWLS, A. W. (Ed.).

Ethnomethodology's Program. Working Out Durkheim's Aphorism, Lanham, Rowman \& Littlefield Publishers, Inc., 2002. p. 263-285.

GARFINKEL, H.; SACKS, H. On Formal Structures of Practical Actions. In: MCKINNEY, J. C.; TIRYAKIAN, E. A (Eds.), Theoretical Sociology: Perspectives and Developments, New York: AppletonCentury-Crofts, 1970. p. 338-366. 
GOODWIN, C. Conversational Organization: Interaction Between Speakers and Hearers. New York: Academic Press, 1981a.

GOODWIN, C. Conversational Organization. New York: Academic Press, $1981 \mathrm{~b}$.

GOODWIN, C. Action and embodiment within situated human interaction. Journal of Pragmatics, v. 32, n. 10, p. 1489-1522, 2010.

GURWITSCH, A. The Field of Consciousness. Pittsburgh: Duquesne University Press, 1964.

HEATH, C. "Interactional participation": the coordination of gesture, speech and gaze. In: D'URSO, V., LEONARDI, P. (Eds.), Discourse Analysis and Natural Rhetoric. Padua, Italy: Cleup Editore, 1983. p. 85-97.

HEATH, C. Body Movement and Speech in Medical Interaction. Cambridge, CUP, 1986.

HERITAGE, J. The epistemic engine: sequence organization and territories of knowledge. Research on Language and Social Interaction, [S.1.], v. 45, n. 1, p. 30-52, 2012.

HISTORY PLAY. Acontece o escândalo chamado Irã-Contras. 2019. Disponível em: $<$ https://br.historyplay.tv/hoje-na-historia/acontece-o-escandalo-chamado-ira-contras $>$. Acesso em: 21 set. 2019.

HUTCHBY, I. Resisting the incitement to talk in child counselling: aspects of the utterance 'I don't know'. Discourse Studies, [S.1.], v. 4, n. 2, p. 147-168, 2002.

JEFFERSON, G. Transcript notation. In: ATKINSON, J. M.; HERITAGE, J. Structures of Social Action: studies in conversation analysis. New York: Cambridge University Press, 1984. p. ix-xvi.

KEEVALLIK, L. Abandoning dead ends: The Estonian junction marker maitea 'I don't know', Journal of Pragmatics, v. 106, p. 115-128, 2016.

LIBERMAN, K. The Reflexivity of Rules in Games. In: LIBERMAN, K. More Studies in Ethnomethodology. State University of New York Press, 2013. p. 83-134.

LYNCH, M.; BOGEN, D. The Truth-Finding Engine. In: LYNCH, M.; BOGEN, D. The Spectacle of History: Speech, Text, and Memory at the Iran-Contra Hearings. Durham, NC: Duke University Press, 1996. p. 122-153.

LYNCH, M.; BOGEN, D. 'My memory has been shredded': A non-cognitivist investigation of 'mental' phenomena", In TE MOLDER, H.; POTTER, J (Eds.) Conversation and Cognition. Cambridge: Cambridge University Press, 2005. p. 226-240.

MEEHAN, A. J. Egon Bittner and the Language Practices of the Police. Ethnographic Studies 15, p. 159188,2018

MONDADA, L. The local constitution of multimodal resources for social interaction. Journal of Pragmatics, n. 65, p. 137-156, 2014.

MONDADA, L. Conventions for multimodal transcription. MAINLY: Multimodal (Inter)actions Lyon, Lyon, 2018. Disponível em: <

https://franzoesistik.philhist.unibas.ch/fileadmin/user_upload/franzoesistik/home/Personen/Mondada/Unt erordner/Mondada_conv_multimodality.pdf >. Acesso em: 18 dez. 2019.

MONDADA, L. Contemporary issues in conversation analysis: Embodiment and materiality, multimodality and multisensoriality in social interaction. Journal of Pragmatics n. 145, p. 47-62, 2019.

PINTO, P. J. G. Práticas de apurar crimes em interrogatórios policiais: uma abordagem da Análise da Conversa Etnometodológica. 2015. 325 f. Tese (Doutorado em Linguística) - Programa de Pós-Graduação em Linguística, Universidade Federal de Juiz de Fora, Juiz de Fora, 2015.

POMERANTZ, A. Agreeing and disagreeing with assessment: Some features of preferred/dispreferred turn shapes. In: ATKINSON, J. M.; HERITAGE, J. Structure of Social Action: Studies in Conversation Analysis. Cambridge: Cambridge University Press, p. 57-101, 1984.

RAYMOND, G. Grammar and social organization: Yes/no interrogatives and the structure of responding. American Sociological Review, [S.1.], v. 68, n. 6, p. 939-967, 2003. Doi: 10.2307/1519752

SACKS, H. On doing "being ordinary”. In: ATKINSON, J. M.; HERITAGE, J. (Eds.) Structures of Social Action: Studies in Conversation Analysis. Cambridge, U.K., Cambridge University Press, 1984. p. 413-429.

SACKS, H. On the Preferences for Agreement and Contiguity in Sequences in Conversation. In: BUTTON, G.; LEE, J. R. E., Talk and Social Organisation (Eds.). Clevedon: Multilingual Matters, 1987. p. 54-69.

KONRAD, Paola Gabriela; OSTERMANN, Ana Cristina. “Tu sabe? Te lembra?”: o resguardo de informações em interrogatórios policiais por meio da (com)posição de perguntas e respostas. Linguagem em (Dis)curso LemD, Tubarão, SC, v. 20, n. 1, p. 73-95, jan./abr. 2020. 
SACKS, H. Lectures on Conversation. Oxford, Basil Blackwell, vol. 1 e 2, 1992.

SACKS, H.; SCHEGLOFF, E. A. Home position. Gesture v. 2, n. 2, p. 133-146, 1975 [2002].

SACKS, H.; SCHEGLOFF, E. A.; JEFFERSON, G. A simplest systematics for the organization of turntaking for conversation. Language, [S.1.], v. 50, n. 4, p. 696-735, 1974.

SCHEGLOFF, E. A. On some questions and ambiguities in conversation. In: ATKINSON, J. M.; HERITAGE, J. (Eds.). Structures of Social Action: Studies in conversation analysis, 1984a. p. 28-52.

SCHEGLOFF, E. A. On some gestures' relation to talk. In: ATKINSON, J. M.; HERITAGE, J. (Eds.), Structures of Social Action: Cambridge: Cambridge University Press, 1984b. p. 266-296.

SCHEGLOFF, E. A. Reflections on Quantification in the Study of Conversation. Research on Language and Social Interaction, v. 26, n. 1, p. 99-128, 1993.

SCHEGLOFF, E. A. Whose Text? Whose Context? Discourse \& Society, v. 8, n. 2, p. 165-187, 1997.

SCHEGLOFF, E. A. Overlapping talk and the organization of turn-taking for conversation. Language in Society, n. 29, p. 1-63, 2000.

SCHEGLOFF, E. A. Sequence Organization in Interaction: A Primer in Conversation Analysis. Cambridge: Cambridge University Press, 2007.

SELTING, M.; AUER, P.; BARTH-WEINGARTEN, D.; BERGMANN, J.; BERGMANN, P.; BIRKNER, K.; COUPER-KUHLEN, E.; MEYER, C.; OBERZAUCHER, F.; UHMANN, S. A system for transcribing talk-in-interaction: GAT2 translated and adapted for English by Elizabeth Couper-Kuhlen and Dagmar Barth-Weingarten. Gesprächsforschung - Online-Zeitschrift zur verbalen Interaktion, [S.1.], v. 12, p. 1-51, 2011.

SILVA, C. R.; ANDRADE, D. N. P.; OSTERMANN, A. C. Análise da Conversa: Uma breve introdução. ReVEL, [S.1.], v. 11, n. 13, p. 1-21, 2009.

STIVERS, T. Sequence Organization. In: SIDNELL, J.; STIVERS, T. (Eds.). The Handbook of Conversation Analysis. Chichester, UK: Wiley-Blackwell, 2013. p. 191-209.

STREECK, J.; GOODWIN, C.; LeBARON, C. Embodied Interaction: language and body in the material world. New York: Cambridge University Press, 2011.

WATSON, R. Harvey Sacks's Sociology of Mind in Action. Theory, Culture \& Society, v. 11, n. 4, p. 169 $186,1994$.

WATSON, R.; GASTALDO, É. Análise da Conversa: etnométodos para conversar. In: WATSON, R.; GASTALDO, É. Etnometodologia \& Análise da Conversa, Petrópolis/Rio de Janeiro: Vozes / PUC-Rio, 2015. p. 87-152.

\section{ANEXO 1 - CONVENÇÕES DE TRANSCRIÇÃO14}

\begin{tabular}{|l|l|}
\hline$(1.8)$ & Pausa \\
\hline$()$. & Micropausa \\
\hline$=$ & Fala colada \\
\hline$[$ Texto] & Falas sobrepostas \\
\hline, & Entonação contínua \\
\hline$\uparrow$ texto & Entonação ascendente da sílaba \\
\hline$\downarrow$ texto & Entonação descendente da sílaba \\
\hline. & Entonação descendente da Unidade de Construção de Turno \\
\hline$?$ & Entonação ascendente da Unidade de Construção de Turno \\
\hline- & Marca de interrupção abrupta da fala \\
\hline$:::$ & Alongamento de som \\
\hline$>$ Texto $<$ & Fala acelerada \\
\hline$>$ Texto $<<$ & Fala muito acelerada \\
\hline
\end{tabular}

${ }^{14}$ Modelo de transcrição traduzido e adaptado pelo grupo de pesquisa Fala-em-Interação em Contextos Institucionais e Não Institucionais a partir da proposta de Jefferson (1984), incorporando sugestões de GAT2 (SELTING et al., 2011).

KONRAD, Paola Gabriela; OSTERMANN, Ana Cristina. “Tu sabe? Te lembra?”: o resguardo de informações em interrogatórios policiais por meio da (com)posição de perguntas e respostas. Linguagem em (Dis)curso LemD, Tubarão, SC, v. 20, n. 1, p. 73-95, jan./abr. 2020. 


\begin{tabular}{|l|l|}
\hline$<$ Texto $>$ & Fala mais lenta \\
\hline$<<$ Texto $>>$ & Fala muito mais lenta \\
\hline TEXTO & Fala com volume mais alto \\
\hline${ }^{\circ}$ texto $^{\circ}$ & Volume baixo \\
\hline${ }^{\circ}{ }^{\circ}$ texto $^{\circ 0}$ & Volume muito baixo \\
\hline$\underline{\text { Texto }}$ & Sílaba, palavra ou som acentuado \\
\hline (Texto) & Dúvidas da transcritora \\
\hline Xxxx & Fala inaudível \\
\hline$(($ Texto $))$ & Comentários da transcritora \\
\hline Hhhh & Riso aspirado \\
\hline Hahahehehihi & Risada com som de vogal \\
\hline$\{\{$ rindo $\}$ texto $\}$ & Turnos ou palavras pronunciadas rindo \\
\hline hhh & Inspiração audível \\
\hline
\end{tabular}

ANEXO 2 - CONVENÇÕES DE TRANSCRIÇÃO MULTIMODAL 15

\begin{tabular}{|c|c|}
\hline \multicolumn{2}{|c|}{ Trajetória dos Gestos } \\
\hline +----+ & Delimitação de início e fim do gesto. \\
\hline,$+ *$ & $\begin{array}{l}\text { A fala transcrita comporta os símbolos gráficos indicadores de gestos }(+, * \text {, por } \\
\text { exemplo) posicionados no momento em que são realizados com relação à fala. }\end{array}$ \\
\hline$(1.0)+*(0.2)$ & $\begin{array}{l}\text { Se um gesto começa no meio de uma pausa, segmenta-se a pausa. (ex.: } 1.2 \\
\text { segundos=1.0 }\end{array}$ \\
\hline$---->121$ & Continuação do gesto até a linha 21 (exemplo) do excerto. \\
\hline$----->+$ & $\begin{array}{l}\text { Se um gesto continua nas linhas seguintes, sua descrição é seguida de uma flecha } \\
\text { que remete ao símbolo que delimita sua finalização. }\end{array}$ \\
\hline$----->>$ & Continuação do gesto até o fim do excerto. \\
\hline \multicolumn{2}{|c|}{ Inserção de Imagens } \\
\hline Ima & $\begin{array}{l}\text { Imagens reproduzidas no texto da transcrição extraídas por captura de tela do } \\
\text { vídeo. }\end{array}$ \\
\hline \# & $\begin{array}{l}\text { Indicador do momento exato que corresponde à imagem (ima) sincronizada ao } \\
\text { turno de fala. }\end{array}$ \\
\hline
\end{tabular}

${ }^{15}$ Modelo de transcrição a partir da proposta de Mondada (2018), traduzidas por Cruz et al. (2019).

KONRAD, Paola Gabriela; OSTERMANN, Ana Cristina. “Tu sabe? Te lembra?”: o resguardo de informações em interrogatórios policiais por meio da (com)posição de perguntas e respostas. Linguagem em (Dis)curso LemD, Tubarão, SC, v. 20, n. 1, p. 73-95, jan./abr. 2020. 